University of Nebraska - Lincoln

DigitalCommons@University of Nebraska - Lincoln

$12-12-2018$

\title{
Design and methodology of a cluster-randomized trial in early care and education centers to meet physical activity guidelines: Sustainability via Active Garden Education (SAGE)
}

\author{
Rebecca E. Lee \\ Arizona State University, releephd@yahoo.com \\ Elizabeth Lorenzo \\ Arizona State University \\ Jacob Szeszulski \\ Arizona State University \\ Anel Arriola \\ Arizona State University \\ Meg Bruening \\ Arizona State University
}

See next page for additional authors

Follow this and additional works at: https://digitalcommons.unl.edu/usdaarsfacpub

Lee, Rebecca E.; Lorenzo, Elizabeth; Szeszulski, Jacob; Arriola, Anel; Bruening, Meg; Estabrooks, Paul A.; Hill, Jennie; Marsiglia, Flavio F.; O'Connor, Teresia; Pollins, Kim Sellers; Shaibi, Gabriel Q.; Soltero, Erica; and Todd, Michael, "Design and methodology of a cluster-randomized trial in early care and education centers to meet physical activity guidelines: Sustainability via Active Garden Education (SAGE)" (2018). Publications from USDA-ARS / UNL Faculty. 2161.

https://digitalcommons.unl.edu/usdaarsfacpub/2161

This Article is brought to you for free and open access by the U.S. Department of Agriculture: Agricultural Research Service, Lincoln, Nebraska at DigitalCommons@University of Nebraska - Lincoln. It has been accepted for inclusion in Publications from USDA-ARS / UNL Faculty by an authorized administrator of DigitalCommons@University of Nebraska - Lincoln. 


\section{Authors}

Rebecca E. Lee, Elizabeth Lorenzo, Jacob Szeszulski, Anel Arriola, Meg Bruening, Paul A. Estabrooks, Jennie Hill, Flavio F. Marsiglia, Teresia O'Connor, Kim Sellers Pollins, Gabriel Q. Shaibi, Erica Soltero, and Michael Todd 


\title{
Design and methodology of a cluster-randomized trial in early care and education centers to meet physical activity guidelines: Sustainability via Active Garden Education (SAGE)
}

\author{
Rebecca E. Lee ${ }^{\mathrm{a}, *}$, Elizabeth Lorenzo ${ }^{\mathrm{a}}$, Jacob Szeszulski ${ }^{\mathrm{b}}$, Anel Arriola ${ }^{\mathrm{a}}$, Meg Bruening ${ }^{\mathrm{b}}$, \\ Paul A. Estabrooks ${ }^{c}$, Jennie Hill ${ }^{c}$, Flavio F. Marsiglia ${ }^{\mathrm{d}}$, Teresia O'Connor ${ }^{\mathrm{e}}$, Kim Sellers Pollins ${ }^{\mathrm{f}}$, \\ Gabriel Q. Shaibi ${ }^{\mathrm{a}}$, Erica Soltero ${ }^{\mathrm{a}}$, Michael Todd ${ }^{\mathrm{a}}$ \\ ${ }^{a}$ Center for Health Promotion and Disease Prevention, College of Nursing and Health Innovation, Arizona State University, Phoenix, AZ, United States \\ ${ }^{\mathrm{b}}$ College of Health Solutions, Arizona State University, Phoenix, AZ, United States \\ ${ }^{\mathrm{c}}$ College of Public Health, University of Nebraska Medical Center, Omaha, NE, United States \\ ${ }^{\mathrm{d}}$ Southwest Interdisciplinary Research Center, Arizona State University, Phoenix, AZ, United States \\ ${ }^{\mathrm{e}}$ USDA/ARS Children's Nutrition Research Center, Baylor College of Medicine, Houston, TX, United States \\ ${ }^{\mathrm{f}}$ Booker T. Washington Early Childhood Learning Center, Phoenix, AZ, United States
}

\section{A R T I C L E I N F O}

\section{Keywords:}

Child

Preschool

Diet

Exercise

Health

Policy

\begin{abstract}
A B S T R A C T
Strategies are needed to help early care and education centers (ECEC) comply with policies to meet daily physical activity and fruit and vegetable guidelines for young children. This manuscript describes the design and methodology of Sustainability via Active Garden Education (SAGE), a 12-session cluster-randomized controlled crossover design trial using community-based participatory research (CBPR) to test a garden-based ECEC physical activity and fruit and vegetables promotion intervention for young children aged 3-5 years in 20 sites. The SAGE curriculum uses the plant lifecycle as a metaphor for human development. Children learn how to plant, water, weed, harvest, and do simple food preparation involving washing, cleaning, and sampling fruit and vegetables along with active learning songs, games, science experiments, mindful eating exercises, and interactive discussions to reinforce various healthy lifestyle topics. Parents will receive newsletters and text messages linked to the curriculum, describing local resources and events, and to remind them about activities and assessments. Children will be measured on physical activity, height, and weight and observed during meal and snack times to document dietary habits. Parents will complete measures about dietary habits outside of the ECEC, parenting practices, home physical activity resources, and home fruit and vegetable availability. SAGE fills an important void in the policy literature by employing a participatory strategy to produce a carefully crafted and engaging curriculum with the goal of meeting health policy guidelines and educational accreditation standards. If successful, SAGE may inform and inspire widespread dissemination and implementation to reduce health disparities and improve health equity.
\end{abstract}

\section{Introduction}

Engaging young children in activities that provide direct experience with healthy behaviors holds promise for stemming the development of obesity and related health-compromising conditions throughout the lifecourse. Promoting the development of healthy habits in early childhood is a public health priority [1-3]. The 2011 Institute of Medicine's (IOM) Early Childhood Obesity Prevention Policies Report identified early care and education centers (ECEC) as a primary target for behavioral interventions, because most young children ( $<5$ years) attend them [3]. Lack of physical activity and fruit and vegetable intake in early childhood contribute to obesity and numerous other healthcompromising conditions, which are high among ethnic minority populations, particularly Hispanics or Latinos (HL) [1,2,4]. Involving ECEC staff, parents and community members in the development and implementation of interventions allows researchers to tap into their deep knowledge of the community and children in their care, thus helping to create an intervention that has a high potential for success

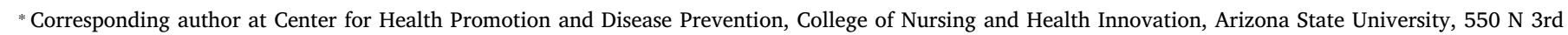
Street, Phoenix, AZ 85004, United States.

E-mail address: releephd@yahoo.com (R.E. Lee). 
[5].

People of HL origin are the largest ethnic minority group in the US $(\sim 17 \%$ of the population) and are expected to represent nearly onethird of the population by 2050 [6]. Nevertheless, like other minority groups, HL have been historically underrepresented in research due to provider misperceptions based on stereotypes, lack of access to care, and concerns around immigration [7-11]. HL suffer disparities across a range of health outcomes related to overweight and obesity [12], owing in part to insufficient physical activity, increased sedentary time, and lack of fruit and vegetable intake [13,14]. Participatory approaches may help to ameliorate these issues by building trust with the community through partnerships that increase understanding of the value of research, and access to research opportunities where community members play a role in the research, and improve their own healthrelated decision making [15]. HL in the US represent many countries, but often share cultural qualities such as emphasis on relationships and interconnectedness (personalismo), strong orientation and commitment to family (familismo), and a strong linguistic base in Spanish [16]. HL have historically been less likely to use childcare in the US [17], but this trend is changing, particularly in areas with high concentrations of HL populations $[18,19]$. These qualities also make transcultural interventions-easily adopted and engaging across cultures-very important [5]. Involving community partners can help to bridge cultural disconnects leading to adoption of evidence-based policies, and to increasing knowledge, improving health, and bringing the voice of the $\mathrm{HL}$ community to the research table.

Community-based participatory research (CBPR) approaches are inherently ecologic, incorporating voices from community members, practitioners, and policy makers. Thus, this study was guided by the Ecologic Model of Physical Activity (EMPA) [20,21], which posits that micro-level environmental settings like ECEC can create opportunities for physical activity and for fruit and vegetable consumption that can directly determine day-to-day choices. The EMPA further suggests dynamic linkages such that health promotion efforts in ECEC may produce secondary impacts in the home environment (and vice versa) via exoenvironmental linkages (e.g., greater parent awareness, home availability of fruit and vegetables owing to child requests based on experiences in ECEC) [22,23] and potentially influencing macro-level policies to reduce health disparities.

SAGE was conceived using state-of-the-art science coupled with community ingenuity to develop an innovative, garden-based, developmentally appropriate curriculum that uses the plant lifecycle as a metaphor for human development. SAGE was developed in a 3-year CBPR partnership development project, refined and pilot tested in two small scale studies in Houston and Phoenix in an additional 3-year CBPR project, and then refined once more in a third pilot test in Phoenix, for a total of 7 years of careful development. These experiences have led to the study presented herein that merged the best of science and community [5,24]. The primary objective of the SAGE cluster-randomized controlled design trial is to determine the impact, transfer, and delivery of a garden-based ECEC physical activity and fruit and vegetables promotion intervention to improve health habits in HL children aged 3-5 years. Guided by the RE-AIM framework (Reach, Efficacy/Effectiveness, Adoption, Implementation, Maintenance) [25] efficacy of the intervention will be examined on physical activity and dietary habits outcomes in children, and intervention transfer will be examined by documenting the secondary impacts on parenting practices and improvements in the home environment to include greater access to physical activity resources and fruit and vegetables availability. Secondary objectives are to investigate the process of delivery by measuring the reach, adoption, and implementation of the intervention.

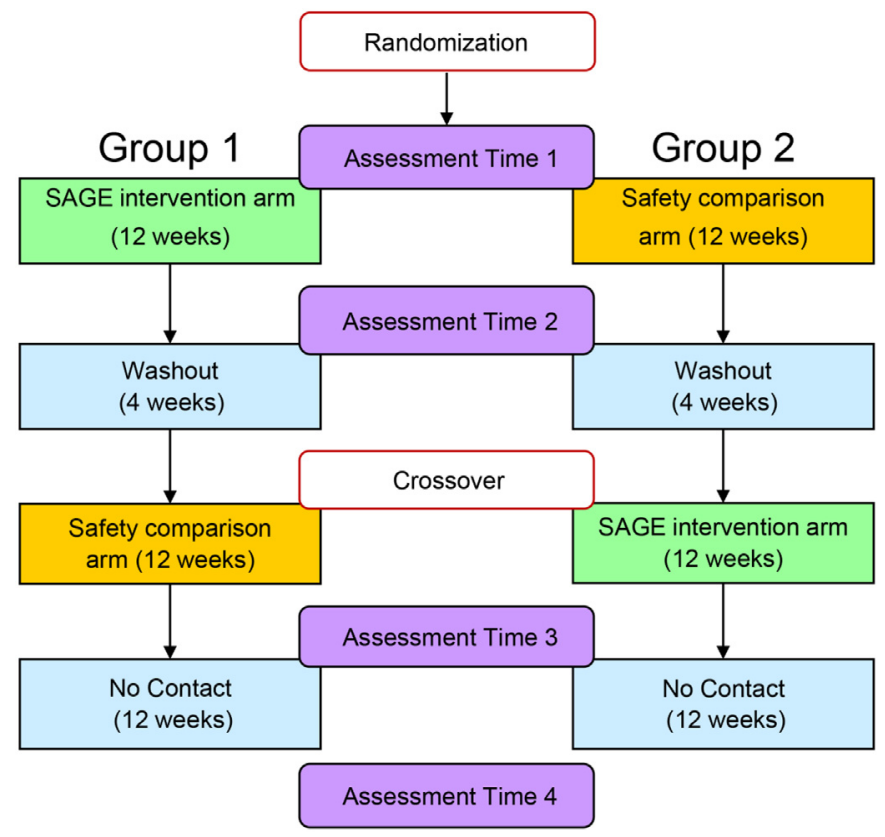

Fig. 1. Flow of SAGE study after participant enrollment.

\section{Methodology}

\subsection{Study overview and design}

SAGE consists of a 12-session, garden-based interactive curriculum delivered in ECEC to increase physical activity and fruit and vegetables consumption $[5,26]$. This study describes the methodology of the cluster-randomized controlled, crossover trial implemented in 28 ECEC sites in three cohorts over three years. The flow of the study is presented in Fig. 1.

\subsection{Geographic setting}

Phoenix is the 6th largest city in the US, with over 1.5 million residents in the city itself and over 4 million in the metropolitan area; it comprises 518 mile $^{2}$. The City of Phoenix is $47 \%$ white non-Hispanic, $41 \%$ Hispanic or Latino, $7 \%$ black or African American, $4 \%$ of more than one race, and $2 \%$ American Indian. Over $80 \%$ have at least a high school education, and the average median household income is $\$ 47,866$ [27]. Hispanic families in Arizona tend to have poorer educational outcomes and are more likely to live in lower socioeconomic (SES) areas than are white families in Arizona, suggesting a need to enhance educational settings and have elements (e.g., linguistic accessibility) tailored for them [19]. Information about ECEC and participants is presented below (Fig. 2).

\subsection{Community Advisory Board (CAB)}

The $\mathrm{CAB}$ has in the past and continues to comprise community leaders who represent the gardening, early childcare, local and state government, and health communities in Phoenix, and parents. As has been done throughout the development of SAGE, the CAB elects a chair and determines governing policies at the beginning of the study to enhance parent engagement; gives technical support to ECEC to monitor timelines, data collection, and development of materials; and advises the PI and scientific team on all aspects of the project. In bimonthly meetings (see below), the CAB and the scientific team identify and implement short-term and long-term goals for developing the partnership and the SAGE project. CAB members are paid a modest honorarium of $\$ 100$ annually, and the chair, $\$ 200$. In addition to the 


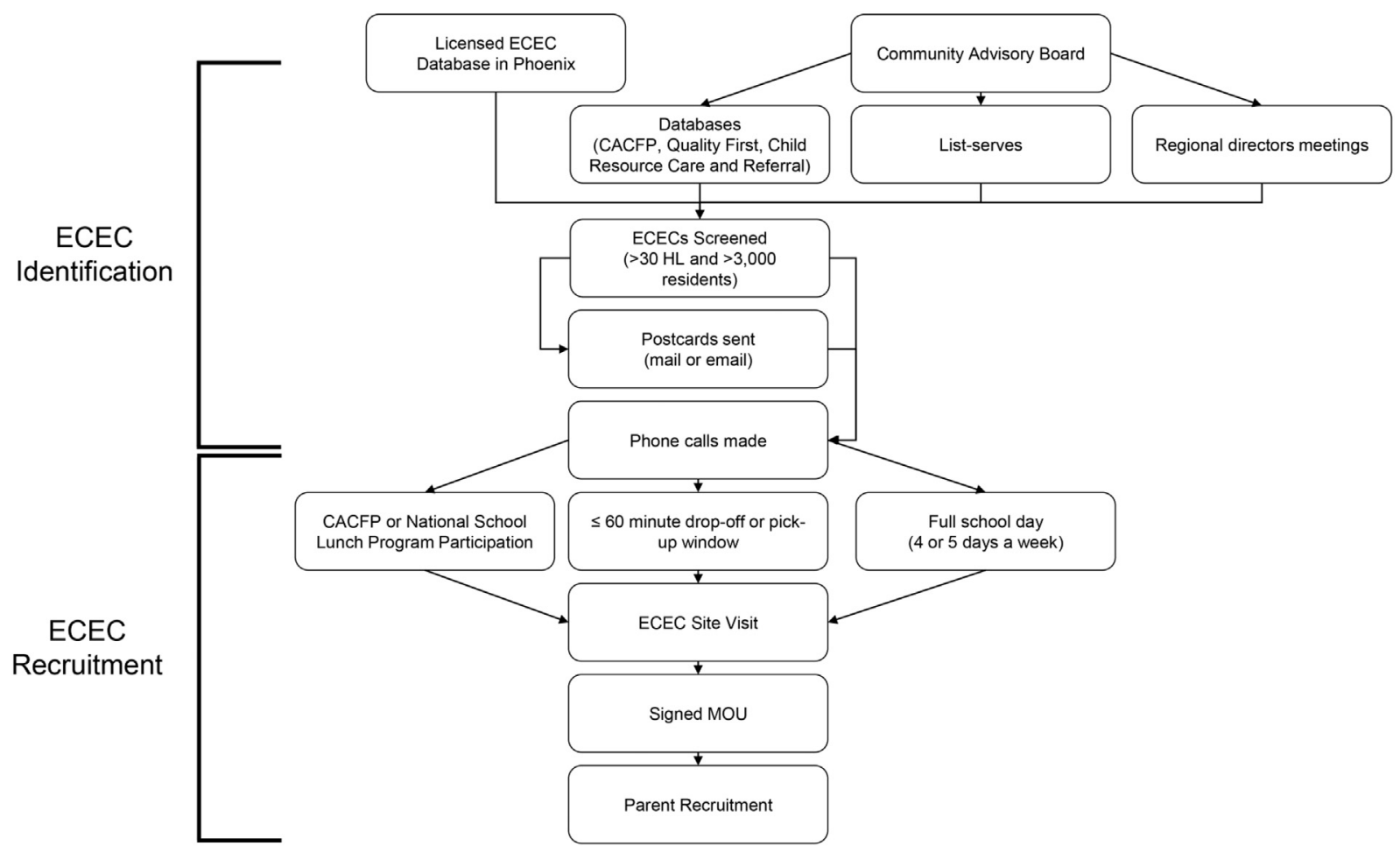

Fig. 2. Flow of early care and education center identification and recruitment strategy.

benefits of improving the community knowledge base and providing a bridge and infrastructure between the scientific expertise and community experience, the $\mathrm{CAB}$ may determine other outcomes and benefits to be reported to the community.

\subsection{ECEC and participant eligibility and recruitment}

Recruitment of ECEC will occur using two simultaneously implemented approaches. One approach begins with compiling a list of all licensed ECEC in the city of Phoenix. Given that ECEC in Phoenix have no indexed information on Hispanic enrollment [28], we will select ECEC within census tracts with $>30 \%$ HL population to contact, to help recruit a primarily HL sample [29-32]. We will also select ECEC in census tracts [33] with at least 3000 residents to avoid selecting rural tracts or those that are in protected terrain. This represents approximately $28.5 \%$ of the possible 900 census tracts in which ECEC could be contacted. The second recruitment approach capitalizes on relationships that our community advisory board has built within the early care and education (ECE) community in Phoenix. We will attend regional ECEC directors' meetings to present our project and send out recruitment postcards via multiple ECE email listservs. In addition, our community advisory board members will connect us with lists of ECEC that participate in Children and Adult Care Food Program (CACFP), Quality First through First Things First of Arizona, or Child Care Resource and Referral. These lists will be used to identify centers in qualifying census tracts (described above) that are eligible to participate. Last, ECEC must have an appropriate space (accessible to children during the school day, adequate sun exposure) for the garden (see below).

Based on previous $\mathrm{CAB}$ suggestions, we will send a colorful and inviting postcard to ECEC directors identified through lists and follow up within one week with a phone call and email to describe the project and invite the ECEC to participate. For centers that contact the study without having received an invitation, we will ask for a physical address to ensure that the center was located in a qualifying census tract before inviting the ECEC to participate. If a director oversees more than one ECEC, all of that director's ECEC are invited to participate, to prevent contamination of future cohorts, although a majority of centers must be located within a qualifying census tract. ECEC will be examined for eligibility in the order that they express interest.

To be eligible for the study ECEC will have to participate in CACFP or the National School Lunch program, be a full-day school where children attend 4 or 5 days of the week, and have a drop-off/pickup window of fewer than 60 min during which research team members could meet with parents. Once eligibility is determined, members of the research team will visit each site in person for a brief meeting to introduce the project further to directors and staff and provide more information. At these meetings, the SAGE team will discuss the garden placement, SAGE schedule and school calendar with the ECEC directors and staff. A follow up email will solidify the relationship with a memorandum of understanding that recaps agreements made during the meeting and calendar dates for assessments and implementation. Family homes and residential ECEC facilities, such as foster family or group homes, will be excluded because of the risk of children being related to caregivers, which can bias responses to surveys and interviews [34].

After ECEC are recruited, parents and/or caregivers will be recruited. Teachers will distribute informational materials in English and Spanish to eligible parents at child pick up/drop off or other events and meetings. Bilingual members of the SAGE team will attend parent meetings, ECEC board meetings or events at ECEC and provide additional information to parents, board members and other interested parties. Participants will be eligible if they are enrolled at the selected ECEC and are 3 to 5 years of age. All children who are enrolled in participating classrooms at an ECEC will be invited to engage in SAGE activities as part of the regular school day, but children who will participate in measurements will need to have a parent who is willing to allow the child to participate in assessments along with completing parent assessments (described below). Only one child per family will be allowed to participate in measurements to avoid within-family nesting effects. In the case of multiple from the same family attending the same ECEC, one child from that family will be randomly selected to participate in the study. 


\begin{tabular}{|c|c|}
\hline Topic & Objectives \\
\hline Where Does My Food Come From? & $\begin{array}{l}\text { - Demonstrate life cycle of a plant } \\
\text { - Describe planting, feeding, watering, growing, and harvesting process }\end{array}$ \\
\hline Nutrients for Growth & $\begin{array}{l}\text { - Understand importance of physical activity and eating fruits and vegetables for } \\
\text { growth and development }\end{array}$ \\
\hline I don't Want to be a Couch Potato! & - Understand importance of healthy diet for energy to be physically active \\
\hline It's a Watery World & $\begin{array}{l}\text { Understand the importance of drinking adequate amounts of water to stay healthy } \\
\text { and hydrated for physical activity }\end{array}$ \\
\hline Chart the Growth & $\begin{array}{l}\text { - Describe the plant growth process from seedling, to fruit, to harvest } \\
\text { - Understand need for water, fruits, vegetables, and physical activity to grow healthy } \\
\text { and strong }\end{array}$ \\
\hline Hungry Humans, Hungry Plants & $\begin{array}{l}\text { - Understand nutrients needed to fuel the body } \\
\text { - Understand what the body needs to grow healthy and strong }\end{array}$ \\
\hline Am I Hungry, Just Right or Too Full? & $\begin{array}{l}\text { - Understanding of hunger and fullness cues } \\
\text { - Describe sensations of hunger and fullness }\end{array}$ \\
\hline Eating to Make my Body Strong! & $\begin{array}{l}\text { - Describe importance of consuming a variety of fruits and vegetables for growth and } \\
\text { development }\end{array}$ \\
\hline Being Active in the Garden & - Understand gardening as a fun way to be physically active \\
\hline Nutrients to Stay Healthy & $\begin{array}{l}\text { - Understand that plants and humans need water and nutrients to remain healthy } \\
\text { - Understand humans need water and nutrients for energy to be physically active }\end{array}$ \\
\hline Time to Harvest! & - Learn how to properly harvest, wash, and store produce from the garden \\
\hline SAGE Garden Party! & - Demonstrate to parents favorite songs, games, activities from the curriculum \\
\hline
\end{tabular}

Safety Curriculum

Topic

Objectives

Bicycle Safety

- Describe what stop and traffic control signs and signals mean

- Describe steps to cross the street with a bicycle

- Describe the protective gear to use when riding a bicycle, tricycle, or scooter

First Aid

- Describe the contents of a first aid kit and what they are used for

- Describe how to apply a Band-Aid

Fire Safety

- Describe home fire hazards

- Describe how to call 9-1-1 in a fire emergency

- Demonstrate how to stop, drop, and roll

Pedestrian Safety

Swim Safety

Kitchen Safety

Smoking

Dogs and Pets

Playground Safety

Stranger Safety

Seatbelt Safety

Firearm Safety

Sun Safety

Dental Hygiene

Personal Hygiene

Personal Wellness
- Describe what different traffic and pedestrian signals mean

- Identify rules to follow when around a swimming pool

- Identify safe behaviors and/or items at the pool and beach

- Identify injury safety concerns found in the kitchen

- Identify kitchen hazards

- Identify how smoke makes different parts of their body feel

- Identify the differences between a smoker and non-smokers' lungs

- Describe the three points of dog Safety (DOG)

- Demonstrate how to appropriately pet a domestic animal

- Describe what to do if chased by a dog

- Describe why playground safety is important

- Identify safe playground practices from unsafe playground practices

- Describe at least 3 important playground safety rules for the classroom

- Describe the difference between a safe and dangerous stranger

- Recognize and describe what to do in a dangerous stranger situation

- Identify what a safe stranger looks like

- Explain the need for a car or booster seat to keep safe

- Create a reminder for family to buckle up and be safe

- Describe how to buckle a seat belt

- Describe the four rules of gun safety

- Demonstrate the four rules of gun safety

- Identify sun safe behaviors

- Describe clothing choices for sun protection

- Create a sun visor for sun protection

- Describe how to brush teeth

- Explain importance of flossing

- Describe what happens to teeth when they are not brushed

- Describe the five steps of hand washing

- Describe how germs spread

- Demonstrate the hand washing process

- Explain why people go to the doctor

- Identify instruments used at the doctor

- Describe the importance of shots
- Describe the steps to properly cross the street

Fig. 3. SAGE garden and safety curricula topics. 


\subsection{Randomization}

SAGE will be completed in three cohorts varying between 8 and 12 ECEC each. ECEC are randomized within each cohort. Centers will be block matched according to ECEC enrollment size, \% HL enrollment, and census tract median household income where the ECEC is located to help reduce any potential impact that these factors might have on intervention outcomes. HL population and median household income are highly correlated $(r=-0.576, p<0.001)$ in the region, and so it is likely that our sample will be fairly homogenous on these factors, overrepresenting low- to middle-income areas. In the event that multiple centers within a cohort have the same director, those centers will be blocked together to avoid potential cross contamination resulting from one director's centers being assigned to both intervention and control at the same time. The blocks will be randomly assigned via coin toss to receive either the SAGE intervention or safety comparison first (and later cross over to the other condition) within each cohort.

Each block of ECEC will be randomized to the SAGE intervention or a wellness and child safety attention comparison. After 16 weeks, each ECEC crosses over to receive the treatment that was not received initially to ensure that all ECEC received both curricula, per community wishes and as an added benefit to the design, allowing continued investigation of longitudinal effects. The SAGE intervention in both cohorts coincides with the typical school year, another CAB suggestion. This study was approved by the Institutional Review Board at Arizona State University and is registered at www.clinicaltrials.gov (NCT03261492).

\subsection{Gardens}

Gardens ( $\left.4^{\prime} \times 6^{\prime}\right)$ will be installed in ECECs prior to the SAGE garden intervention. Each ECEC director and the SAGE team will identify an appropriately sunny and protected location on the property. Gardens are built such that a child can stand at the side of the garden and reach to the center. Cinderblocks will form the frame around each garden, and the frame will be filled with common garden soil. Climate appropriate fruits, vegetables, and herbs will be planted in advance of the curriculum with the aid of teachers and ECEC staff so that plants will be available throughout the SAGE curriculum. ECEC personnel will take primary responsibility for watering the garden with additional help from the SAGE team when the SAGE team visits the site for recruitment, assessments, and intervention delivery.

\section{Intervention}

The SAGE curriculum was developed through a CBPR approach to meet national guidelines [3] and accreditation standards [35]. IOM recommendations, generally consistent with other recommendations (e.g., USDA) [36,37], included increasing physical activity to at least 15 min per hour during the time children spent at ECEC, with daily outdoor time, having developmentally appropriate structured and unstructured physical activity, integrating physical activity into social and cognitive activities, increasing access to places and spaces that help promote physical activity, helping adults to be active with children, and training for ECEC teachers to increase children's physical activity, as well as improving dietary habits by exposing children to an environment that helps to promote eating a variety of foods, understanding hunger and fullness cues, and training caregivers how to encourage and support these behaviors [3].

Formative interviews with ECEC directors identified the need for an innovative curriculum that focused on health and dietary habits to comply with accreditation guidelines. The scientific team took this information along with information from existing garden-based curricula and protocols to be adapted and integrated for use in a SAGE feasibility trial [24,38-40]. The scientific team also reviewed research to conceptualize a developmentally appropriate and center-based protocol to train children on hunger and fullness cues [41-45]. Together, an outline was conceived of possible topics and activities that two ECE teachers and two parents then reviewed. The ECE curriculum was also designed to meet National Association for the Education of Young Children (NAEYC) accreditation standards [35].

The resulting SAGE curriculum is a garden-based physical activity and nutrition educational program and includes 12 sessions that can be delivered at the ECEC as frequently as desired (daily, weekly), with component parts that can also be sprinkled throughout the school day at an appropriate frequency that "fits" within existing curricula as presented in Fig. 3. The SAGE curriculum is flexible to accommodate holidays, bad weather days, and other breaks (e.g., testing, field trips). SAGE includes 3 active learning songs and 13 games led by the teacher that increase understanding of concepts while doing physical activity during the session (e.g., pantomiming the lifecycle of a plant, acting out the role of the farmer). Children learn actively how to plant, water, weed, harvest (walking around, carrying watering cans, watering the garden, tending the garden, playing garden-based games, garden exploration), and do simple food preparation involving washing, cleaning, and sampling fruit and vegetables. SAGE demonstrates how engaging in daily physical activity by tending the garden can contribute to meeting physical activity guidelines [46]. Additional activities in the curriculum include 3 science experiments, a mindful eating exercise in every session (a taste test including either store bought or garden grown produce), and 22 interactive discussions to reinforce various healthy lifestyle topics (e.g., fruit, vegetable and water consumption, importance of physical activity, hunger and fullness cues).

\subsection{Crossover comparison}

The attention comparison arm will participate in a child wellness and safety curriculum. The wellness and safety curriculum includes concepts and lessons for educating young children on bicycling, first aid, fire, pedestrian, swim, kitchen, smoking, dogs and pets, stranger, seatbelt, firearm, sun, and playground safety, dental and personal hygiene, and was designed to accommodate the needs of a variety of types of ECEC. Preexisting government or national nonprofit programming [47-49] was reviewed and integrated into lesson plans and accompanying materials to create an outline of topics and learning experiences that reflected NAEYC standards [35]. The initial outline for topics to be included was reviewed and vetted by the $\mathrm{CAB}$, and any gaps in topics, lesson plans and materials were identified and addressed, following a collaborative and iterative process. The complete child wellness and safety curriculum was packaged together in a single binder that included handouts, coloring sheets, comic books, games, and songs, that were easily implemented with minimal training or preparation. The curriculum binder was modularized, so that the sessions could be taught in any order. Each session has several learning experiences that could be completed all in one session or in separate sessions. The SAGE team will meet with ECEC staff in this condition for one 30-min training session at the beginning of the child wellness and safety curriculum arm. ECEC will be contacted once per month by phone or email to answer questions and provide additional support to help keep engagement high.

\subsection{Parent engagement}

Parents' anecdotal reports and exit interviews with ECEC staff in SAGE pilot studies suggested strategies to enhance completion of parent-derived assessments: payment to parents for the time spent completing measures, higher levels of contact during the study (e.g., text messages, newsletters), and approaching parents at convenient times (e.g., during already scheduled meetings, prescheduled appointments). In an additional focus group, parents confirmed these points, and they added that the benefit of SAGE for their children should be highly emphasized in the study. 
We developed content for newsletters and text messages, to be distributed twice per week, using nominal group technique (NGT). NGT is a well-established, multistep group data collection procedure in which a group generates, collects, and prioritizes responses in reaction to a specified concept or theme [50-53]. NGT reduces group bias and is more efficient for eliciting input than traditional focus groups. The CAB participated in two qualitative, structured NGT groups to generate content about promoting physical activity and fruit and vegetable consumption outside of the ECEC. In addition, the entire investigative team drew on their combined years of experience working with underserved communities to complete a third NGT to generate content for messages about remembering to complete and return assessment materials (e.g., appointment reminders, survey and accelerometer return).

The research team formatted and vetted NGT responses, modifying them into parental text messages that enhanced cultural relevancy (e.g., locally appropriate language, cultural norms, and contextual factors) $[54,55]$. Parents are instructed when they consent to receiving text messages that they may respond to a text at any time to obtain additional information. Next, responses were formatted for content for newsletters, so that weekly newsletter content matched text message content, and translated and back translated to Spanish, the primary language for most parents. Last, three parents completed one focus group in Spanish where they reviewed samples of the newsletters and text messages, and provided additional feedback to ensure cultural relevancy and accessibility.

Parent engagement will begin during recruitment, where parents are given information about SAGE by teachers, greeted by friendly SAGE team members at child pick up and drop off, and given ample opportunity to ask questions in person, by phone, email and from the project website. Parents will also receive a modest remuneration for completing study measures (ranging from $\$ 25$ to $\$ 55$ depending on measures completed and measurement time point). Assessments are prompted by text messages and conducted at ECEC or at another community location during a scheduled appointment. Parents complete surveys electronically on a computer or device (e.g., phone, tablet) or return completed, hard copy surveys during child drop off/pick up. Parents and children received a variety of promotional, SAGE branded items (e.g., t-shirts, hats, reusable grocery bags, water bottles, vegetable peelers) during data collection throughout the study.

\subsection{Teacher development}

One formal teacher training session will be conducted at each ECEC approximately two weeks before implementation. SAGE team members meet for 90 min with teachers, assistant teachers, ECEC directors, and any interested ECEC staff (e.g., kitchen personnel) to discuss the garden-based curriculum, the PRIME principles, and garden maintenance. The research team first presents a brief overview of the SAGE project, emphasizing its development using a participatory approach. In particular, ECEC staff are shown an overview of the curriculum and which federal standards it meets as well as a brief overview of all sessions. Teachers are very interested to learn that the SAGE curriculum meets many required standards, freeing up time that would have been spent on lesson planning, and offers an innovative strategy to engage parents. The SAGE team demonstrates an activity/song and completes a mindfulness eating exercise to help ECEC staff get a sense of what to expect during SAGE sessions. The SAGE team emphasizes key underlying principles and strategies, such as high involvement and participation in activities and avoiding judgmental language during taste tests, instead focusing on how the experiences were perceived by children's five senses.

The PRIME principles were created specifically for SAGE following extensive formative research done in the pilot studies [24] and best practice guidelines [56]. The PRIME acronym was embraced to signify Promoting positive experiences, Room management, Improvement directed reinforcement, Modeling appropriate behaviors, and
Establishing garden maintenance. Promoting positive experiences encourages ECEC staff to help children learn how to make healthier choices by presenting opportunities to engage in easy, fun, interactive and experiential physical activities and taste tests. Room management focuses on roles and responsibilities while SAGE is being implemented to enhance adoption of the new activities. While the SAGE team initially leads sessions, teachers are in charge of classroom management, and after the teachers assume the primary role of implementing SAGE sessions, the SAGE team looks after classroom management. This strategy exposes teachers to SAGE techniques, curriculum and activities before they teach it independently and gives the teachers an opportunity to demonstrate their expertise in classroom management promoting a co-learning environment. Improvement directed reinforcement gives teachers the opportunity to focus on specific behaviors that children are invited to do during the SAGE implementation helping children to learn more efficiently and also drawing teacher attention to specific elements of the curriculum. Modeling appropriate behaviors is the last key strategy to promote teacher engagement and provide examples of how everyone who is in the classroom during SAGE sessions participates in the songs, games, discussions, and activities. Teachers are instructed to model the behaviors themselves and help students to do the healthier behaviors.

The last element of the 90-minute teacher training session involves establishing norms for garden maintenance to help promote adoption, effective implementation and sustainability for future growing seasons. Teachers are instructed on basic garden maintenance, such as regular watering of the garden, inspecting the garden daily for refuse (and removing it promptly), identifying weeds, insects or other threats to the plants, and detecting plants that are ready for harvest as well as making a plan that identifies who is responsible for each of these items.

Additional training occurs during implementation. The first 12 sessions of SAGE are led by the research team over 6 to 8 weeks, with teachers observing and assisting in the SAGE intervention. The 12 sessions are then repeated over a second 6 to 8 week period, led by the teachers with assistance from the research team. A $30 \mathrm{~min}$ booster training session is held about five weeks into implementation as teachers are about to become the primary implementers. The booster session is built around a teacher self-evaluation to help teachers with specific areas in which they may be struggling. In the booster sessions, the PRIME principles will be again emphasized with particular attention to high levels of teacher participation, keeping the children moving as much as possible throughout the session, and avoiding judgmental language. Technical support from the SAGE team is available throughout implementation for ECEC staff via phone and email for those who desire additional help.

\subsection{Sample size calculation}

We propose to recruit a T1 sample size of 336 children plus 336 home caregivers (e.g., parents) -12 children from each of 28 ECEC. Using sample size simulation tools for cluster-randomized trials along with intraclass correlation (ICC, an index of within-ECEC clustering) and variance estimates derived from our pilot data, we found that a complete-case sample size of 280 child-caregiver dyads yielded estimated power $>0.83$ to detect small changes of $2.75 \mathrm{~min} / \mathrm{h}$ MVPA and $4.50 \mathrm{~min} /$ total physical activity under relatively low clustering (ICCs $=0.11,0.19)$ and modest changes $(4.25 \mathrm{~min} / \mathrm{h}$ MVPA, $6.50 \mathrm{~min} /$ $\mathrm{h}$ total physical activity) under strong clustering (ICCs $=0.55,0.60$ ) at $\alpha=0.05$. These differences are smaller than those seen in our pilot data (MVPA differences $=3 \mathrm{~min} / \mathrm{h}, 11 \mathrm{~min} / \mathrm{h}$; total physical activity differences $=5 \mathrm{~min} / \mathrm{h}, 12 \mathrm{~min} / \mathrm{h}$ ) [24]. Given ICC and variance estimates derived from our pilot data, this sample size also afforded power > 0.85 to detect differences in combined fruit and vegetable consumption of 1.20 servings/day. 


\section{Data collection and measures}

Data will be collected from participants (children and their home caregiver or parent) at Time 1: baseline (T1); Time 2: 12 weeks at crossover (T2); Time 3 at 24 weeks, after both groups have completed both treatment and comparison (T3); and at Time 4: follow up, 12 weeks following T3 (T4).

\subsection{Outcome measures}

We will measure efficacy and individual-level maintenance impact and transfer at T1, T2, T3, and T4. Assessments occur at ECEC for children (and at home or at ECEC for parents; see below). Whenever possible, data will be entered directly into online electronic forms (e.g., REDCap) coded by ID number only. When online data collection is not feasible or preferred, participants will be provided paper surveys instead. Child assessments include physical activity, sedentary time, fruit and vegetables consumption, and eating in the absence of hunger. Parents will complete questionnaires to assess demographics, parenting practices, home fruit and vegetables availability, and food security. Assessments will be prompted by text messages and parents could return surveys and devices during child pick up/drop off.

Physical Activity and Sedentary Time. Total minutes of moderate plus vigorous physical activity and sedentary time will be measured by wGT3X-BT accelerometry [57]. Accelerometers are valid and reliable state-of-the-art devices that offer an objective measure of physical activity and have been well received by the community [58]. Children will wear a small accelerometer at their hip during all waking hours for 7 days to assess physical activity and sedentary time, removed only when under water [58-61]. Parents complete logs to record on/off time and received a FAQ, along with prompting and support via text messages or phone.

Accelerometer data will be downloaded into $10 \mathrm{~s}$ epochs, as young children accumulate physical activity in shorter bouts than older children. Sleep and wake times will be determined through visual inspection of the data tracking and compared with self-reported sleep and wake times for accuracy. Non-wear time will be determined using the Choi et al. [62] wear time filter, built into the ActiLife software. We will only include participants in our analysis who have $\geq 2$ days of valid wear time with an average of $\geq 8 \mathrm{~h}$ a day. Daytime physical activity will be analyzed using the Butte et al. [63] activity cut points, and total physical activity (light, moderate and vigorous) will be determined. We will control for differing wear time between participants by residualizing minutes of wear regressed onto total physical activity.

Child fruit and vegetables consumption in the ECEC will be measured by direct observation using a standardized coding sheet. SAGE team members will observe children's consumption at meal and snack times to account for consumption which children are at the ECEC (not in the presence of parents) $[64,65]$. Interobserver reliability for the nutrient intake will be assessed on a random day at least once at each site $[66,67]$. The child's fruit and vegetables consumption outside the ECEC will be measured using a fruit and vegetable screener that asks parents to think about their child's eating habits over the past seven days, and respond how often their child consumes (a) 100\% juice, (b) fruit (not including juice), (c) green salad, (d) potatoes (not including french fries, fried potatoes, and potato chips), (e) carrots, (f) vegetables (not including carrots, potatoes or salad). Parents can respond with $\geq 4$ times a day; 3 times a day; twice a day; once a day; 1-3 times during the past 7 days; 4-6 times during the past 7 days; or my child did not eat any during the past 7 days. The Nutrient Data System for Research (NDSR) will be used to aid in data management and analysis $[68,69]$.

The Eating in the Absence of Hunger test [70] [71], .A validated and age-appropriate assessment, was modified for use in community settings in the SAGE pilots studies [72]. In the current adapted field protocol, we will assess children when they arrive at the ECEC after breakfast or immediately after lunch. Children are first asked if they are hungry or full to control for true hunger. Then, children are presented with snacks (e.g., animal crackers) that are individually pre-measured and presented in a small, resealable plastic bag and coloring books. Children are told that they may eat the snacks or play with the coloring books while the teacher prepares the next activity. After $10 \mathrm{~min}$, children are moved to the next activity. Snacks are weighed before and after the $10 \mathrm{~min}$ period to determine how much they ate.

Parenting practices and home environment. The Preschooler physical activity Parenting Practices (PPAPP) instrument characterizes parenting practices that encourage or discourage children to be physically active. Reported psychometrics are strong, and test-retest reliability (0.56-0.85) is moderate to excellent [60]. The a scale of parenting practices [73] was used to measure Preschooler fruit and vegetables Parenting Practices (PFVPP) measures five categories of parenting practices: teachable moments, practical methods, firm discipline, restriction of junk foods, and enhanced availability and accessibility. Internal consistencies of items varies:0.41-0.58 [73]. The fruit and vegetables Home Availability questionnaire is a self-report instrument that measures fruit and vegetables items in the home and shows strong internal consistency $\alpha=0.79$ among parents of preschoolers [74] and validity with homeinventory checks [75].

\subsection{Process measures}

To determine the process of the delivery of the SAGE intervention, we will combine quantitative and qualitative methods to define key characteristics of adoption, reach, and implementation. Adoption refers to the number, proportion, and representativeness of the ECEC, directors, and teachers who agree to deliver the SAGE intervention. We will gather information on the characteristics of the ECEC (e.g., size, service area), directors, and teachers (e.g., gender, years of employment) who agree to participate in the delivery of the intervention to compare with publically available information via center websites and promotional materials (e.g., websites that outline the center's mission and services) to determine how representative they are of the population of centers, directors, and teachers. We will measure the ratio of the number of ECEC and staff who agree to participate compared with the number eligible that are invited to participate [76].

Reach (proportion and representativeness of the priority population) determines whether the intervention attracts a large and generalizable sample from the intended audience [25,77]: in SAGE, the children and parents who will participate. We will operationalize two forms of reach. First, as the ratio of the number of children and parent participants compared with the number of screened parents and children at ECEC whose parents do not consent or participate. We will also count the number of children who are exposed to the SAGE intervention, but who are not completing measures. We will compare the participants' demographic characteristics to those of the ECEC child population as reported by directors to calculate the sample's representativeness.

Measuring the implementation gives the degree to which the intervention is delivered as intended (dose and fidelity) and potential adaptations [78]. We will define dose as the proportion of contact, content, and materials actually delivered and fidelity as the proportion of the contact, content, and materials delivered compared with what was planned. We created Fidelity Checklists to document all content and activities that will be delivered during each SAGE session [79].

\subsection{Data analysis}

Data will be entered into REDCap, a secure online data collection and management platform. Data originally recorded with paper and pencil will be entered and proofed manually and then combined with data that are recorded directly via REDCap. Following export of data from REDCap, we will perform edit and logic checks on all datasets to insure data integrity and quality. We will conduct preliminary analyses to examine distributional characteristics of measures and bivariate 
associations via descriptive statistics and plots, identify potentially relevant confounders and background covariates, characterize patterns of missing data, conduct basic psychometric analyses, and assess the degree of balance across randomized groups. We will summarize changes in outcomes over time as a function of initial group assignment (SAGE vs. Safety). To identify potentially relevant confounders and background covariates, we will examine bivariate associations among primary and secondary outcome measures and variables believed to influence outcomes. We will determine if patterns of missing data are similar between groups and if "missing-at-random" (MAR) assumptions are tenable. If MAR assumptions are met, we will use full information maximum likelihood (FIML) estimation. If MAR assumptions are not met, we will consider other methods, including multiple imputation (MI) and pattern-mixture models. Using such methods as FIML and MI mitigate the loss of power and potential biases introduced by analyzing only complete cases (i.e., by using listwise deletion).

We will use generalized linear mixed models (GLMM) to test for efficacy and transfer of intervention effects. First, to test initial shortterm (T1 vs. T2) effects, we will estimate GLMMs predicting T2 outcome scores/values from initial Group assignment (SAGE vs. Attention Control), T1 outcome scores, and any relevant confounders and/or background covariates. Next, to test effects in the context of the crossover design, we will estimate GLMMs with scores at T2 and T3 assessments treated as repeated measurements predicted from initial Group assignment (identical to an indicator of intervention sequence here), an indicator of the Intervention received just prior to the assessment (i.e., SAGE or Attention Control), T1 outcome scores, and relevant confounders and/or background covariates. Last, to assess long-term effects, we will estimate GLMMS predicting T4 outcome scores/values from initial Group assignment (SAGE vs. Attention Control), T1 outcome scores, and any relevant confounders and/or background covariates. These tests will be followed by tests of planned contrasts for between-group differences between values at adjacent time points and change across multiple time points (e.g., linear change across T2-T4 assessments).

In all models, center will be treated as a higher-level sampling unit ("cluster"), with potential within-center non-independence (i.e., clustering) in outcome scores accounted for via random ECEC-level intercept components. Within-person error variance/covariance structures for longitudinal models will be selected based on tests of relative model fit. As noted above, we will adjust for relevant background covariates and confounders identified in preliminary analyses. In each model, the link function (e.g., identity, logit) and error type (e.g., Gaussian, binomial) will be chosen based on distributional properties and/or scaling of the outcome measure. We will conduct analyses in PROC MIXED and PROC GLIMMIX under SAS 9.4 [80].

\section{Discussion}

Implementing sustainable strategies for meeting guidelines for preventing obesity in ECEC faces many challenges. These include reaching children and families at greatest risk for developing obesity and related health-compromising conditions, implementing interventions that are easily integrated into existing structures, and providing children with fun and easy experiences that promote interest in, initiation, and maintenance of, healthy habits to last a lifetime. Previous research has reported that throughout the entire day, the place and time where the child is least physically active is in the ECEC [60,81-85]; yet, there has been modest attention to promoting physical activity among younger children in this setting and the quality of the existing limited evidence is low [86]. ECEC classrooms and teachers face challenges with keeping children safe throughout the day; thus, many classroom strategies for maintaining order involve sedentary time, with the notable exception of unstructured play time out of doors. Previous studies have suggested that structured play time may be more effective for promoting greater physical activity in young children compared to unstructured play time $[87,88]$. Interventions that combine clear learning objectives that meet federal health guidelines and educational standards with structured physically active games, songs and other play time activities offer an easily integrated and efficient, value-added strategy for the ECEC setting that can reach many children who are most vulnerable for developing obesity and related health-compromising conditions.

The SAGE project features many innovations not implemented in previous interventions conducted in the ECE setting. Although ecologic frameworks have been previously applied to guide interventions, few studies exist that address not only the multilevel nature of the ecologic milieu but also the dynamic system in which behavior change occurs [89]. This study responds to this gap with a CBPR approach to weave together an established theoretical model, the EMPA [20,21], with a clear evaluation framework (RE-AIM) in a cluster-randomized controlled trial (RCT) using standardized CONSORT reporting guidelines. More efforts such as this are necessary to reduce disparities in HL health and document systematically the multilevel, dynamic process underpinning participant engagement and behavior transformation $[25,90,91]$. Integrating systematic measures of this process such as the RE-AIM framework can then increase the likelihood that, if successful, SAGE could be scaled-up for ready adoption, implementation, and sustainability in ECEC.

SAGE employed a CBPR collaborative process throughout the conceptualization, development, implementation, and testing of the intervention as well as in the process of interpreting and disseminating the findings. CBPR has been endorsed as vital for increasing relevance and sustainability of interventions [92-100]; it allows community members to be equal partners in research activities and identify aspects of inquiry that theorists and researchers alone may miss. The ideas of working with young children and framing an obesity prevention intervention within the context of a garden-based curriculum emerged from the community [101]. Collaborative intervention development meant that the intervention and comparison group strategies, materials and protocols were meaningful and relevant for not only testing a novel intervention strategy to move the science forward but also bestowing great benefit to the community who was served by SAGE: easy to implement, fun for everyone, and an engaging learning experience. In addition, including ECEC staff in the pilot studies developing SAGE helped to infuse the importance of meeting educational standards into the curriculum, in addition to meeting federal guidelines for health behaviors in young children [24].

Although the use of interactive technology to engage participants is not novel, SAGE is among the first to develop and test a text messaging strategy via a CBPR process to augment parent engagement newsletters, prompting parents to interact with their preschooler about classroom activities [102-104]. Relying on the voice of the community whom we serve to understand what kind of information they wanted and needed to help with effective parenting about health behaviors has great intuitive potency, but is rarely used in practice. Furthermore, the notion to employ text messaging as a communication channel-another strategy with intuitive appeal-was also a suggestion from community partners. The resulting combination of both a paper newsletter with colorful pictures, accessible language, and clearly presented information (suitable for putting on the refrigerator with a SAGE themed magnet) and a text message guiding parents to ask children about information presented in the newsletter is a low cost and efficient strategy to keep busy parents engaged. The newsletters also linked parents to valuable community resources and ideas for family friendly physical activities as well as budget-friendly sources for locally procured fruit and vegetables (e.g., local farms, farmers markets). In addition, we included easy, kid friendly recipes (for mother's little helpers) for produce that was in season, bringing added value to families and communities.

The use of a cluster-randomized, crossover design brought many benefits to the study, allowing the scientific team to reap the benefits of 
scientific rigor from a solid experimental design while allowing all participants to experience both arms of the study. Early formative work during the development of the initial partnership that began the process of developing SAGE in Houston suggested that a randomized controlled trial was simply not feasible for a highly engaged community study [5]. Our community told us that all participants in the study had to receive all possible benefits from the study, or they would refuse to enroll. The crossover design introduced greater complexity, but also provided additional benefits of allowing us to evaluate the implementation process over a longer period of time and giving ECEC additional curriculum support in the form of the wellness and safety curriculum. Prior to the development of the wellness and safety curriculum, we conducted a survey with a convenience sample of ECEC to determine the need for a standardized wellness and safety curriculum. Only half (52\%) had any kind of child wellness and safety curriculum; the remaining $48 \%$ said they desired a curriculum and technical support to implement one. Although various federal and non-profit groups have guidelines and suggested activities across a range of topics suitable for young children, there is no widely available, comprehensive and easy to use child wellness and safety curriculum for ECEC that complies with child health and NAEYC standards. Thus, the comparison group succeeded in providing ECEC with an engaging, useful, carefully sequenced, and easy-todeliver curriculum, so that randomization to this group did not influence attrition or reach and effectively served as a placebo (unlikely to affect outcomes of interest).

Last, SAGE fills an important void in the policy literature by employing a participatory strategy to produce a carefully crafted and engaging curriculum with the goal of meeting health policy guidelines and educational accreditation standards. The SAGE trial was theoretically grounded, relying on the EMPA [20,21], integrating macro level policy into micro level classroom settings, and producing meso- and exo-level linkages to family, home and community members. Moreover, although SAGE focused specifically on improving the health of HL, the transcultural nature of gardening - the intrinsic appeal to people from virtually any culture-is highly translatable to other communities. In conclusion, there are few studies investigating strategies to promote physical activity and fruit and vegetable consumption in ECEC, particularly among underserved communities at highest risk for developing obesity and related health-compromising conditions. If successful, SAGE may inform and inspire widespread dissemination and implementation to reduce health disparities and improve health equity by inspiring health for children and families.

\section{Funding}

This current study was supported by a cooperative agreement awarded to Dr. Lee (U01 MD010667-01) from the National Institute on Minority Health and Health Disparities.

\section{Acknowledgements}

The authors deeply thank and acknowledge the many community members and organizations, students and trainees and other unsung heroes and champions who have contributed tirelessly to the success of SAGE.

\section{References}

[1] E.M. Taveras, M.W. Gillman, K. Kleinman, J.W. Rich-Edwards, S.L. Rifas-Shiman, Racial/ethnic differences in early-life risk factors for childhood obesity, Pediatrics 125 (4) (2010) 686-695.

[2] E.M. Taveras, M.W. Gillman, K.P. Kleinman, J.W. Rich-Edwards, S.L. RifasShiman, Reducing racial/ethnic disparities in childhood obesity: the role of early life risk factors, JAMA Pediatr. 167 (8) (2013) 731-738.

[3] S. McGuire, Institute of Medicine (IOM) early childhood obesity prevention policies, Washington, DC: the National Academies Press; 2011, Adv. Nutr. 3 (1) (2012) 56-57.

[4] C.L. Ogden, M.D. Carroll, K.M. Flegal, High body mass index for age among US children and adolescents, 2003-2006, JAMA 299 (20) (2008) 2401-2405.

[5] R.E. Lee, E.G. Soltero, S.K. Mama, F. Saavedra, T.A. Ledoux, L.H. McNiell, Developing a transculutural acadmic-community partnership to arrest obesity, Int Q Community Health Educ. 34 (2) (2014) 215-233.

[6] Profile America Facts for Features, http://www.census.gov/newsroom/releases/ archives/facts for features special editions/cb12-ff19.html, (2012).

[7] NIH Policy and Guidelines on The Inclusion of Women and Minorities as Subjects in Clinical Research - Amended, October, 2001. Accessed August 12, 2015.

[8] B. Evelyn, T. Toigo, D. Banks, et al., Participation of racial/ethnic groups in clinical trials and race-related labeling: a review of new molecular entities approved 1995-1999, J. Natl. Med. Assoc. 93 (12 Suppl) (2001) 18S-24S.

[9] J.A. Fisher, C.A. Kalbaugh, Challenging assumptions about minority pa rticipation in US clinical research, Am. J. Public Health 101 (12) (2011) 2217-2222.

[10] V.W. Pinn, C. Roth, A.C. Bates, R. Wagner, K. Jarema, Monitoring Adherence to the NIH Policy on the Inclusion of Women and Minorities as Subjects in Clinical Research, National Institute of Health, Department of Health and Human Services, Bethesda, MD, 2009.

[11] D. Wendler, R. Kington, J. Madans, et al., Are racial and ethnic minorities less willing to participate in health research, PLoS Med. 3 (2) (2006) e19.

[12] C.L. Ogden, M.D. Carroll, L.R. Curtin, M.M. Lamb, K.M. Flegal, Prevalence of high body mass index in US children and adolescents, 2007-2008, JAMA 303 (3) (2008) 242-249.

[13] P. Gordon-Larsen, L.S. Adair, B.M. Popkin, Ethnic differences in physical activity and inactivity patterns and overweight status, Obes. Res. 10 (3) (2002) 141-149.

[14] P. Gordon-Larsen, K.M. Harris, D.S. Ward, B.M. Popkin, Acculturation and overweight-related behaviors among Hispanic immigrants to the US: the national longitudinal study of adolescent health, Soc. Sci. Med. 57 (11) (2003) 2023-2034.

[15] V. Diaz, Encouraging participation of minorities in research studies, Ann. Fam. Med. 10 (4) (2012) 372-373.

[16] A. Behnke, Working with Latino Parents in Child Care and Other Settings, North Carolina Cooperative Extension Service, 2006.

[17] L. Daugherty, Child Care Choices of Hispanic Families, RAND Graduate School Dissertation Series, (2009).

[18] High-Quality Child Care and Early Education, What Arizona's Parents Want, Arizona Early Childhood Development and Health Board (First Things First), 2012.

[19] Race for Results: Building a Path to Opportunity for all Children, http://www.aecf org/ /media/Pubs/Initiatives/KIDS\%20COUNT/R/RaceforResults/ RaceforResults.pdf, (2014).

[20] R.E. Lee, C. Cubbin, Striding toward social justice: the ecologic milieu of physical activity, Exerc Sport Sci Rev 37 (1) (2009) 10-17.

[21] J.C. Spence, R.E. Lee, Toward a comprehensive model of physical activity, Psychol. Sport Exerc. 4 (1) (2003) 7-24.

[22] S. Heim, J. Stang, M. Ireland, A garden pilot project enhances fruit and vegetable consumption among children, J. Am. Diet. Assoc. 109 (7) (2009) 1220-1226.

[23] T. Baranowski, M. Davis, K. Resnicow, et al., Gimme 5 fruit, juice, and vegetables for fun and health: outcome evaluation, Health Educ. Behav. 27 (1) (2000) 96-111.

[24] R.E. Lee, N.H. Parker, E.G. Soltero, T.A. Ledoux, S.K. Mama, L. McNeill, Sustainability via active garden education (SAGE): results from two feasibility pilot studies, BMC Public Health 17 (1) (2017) 242.

[25] Reach Effectiveness Adoption Implementation Maintenance (RE-AIM). http:// www.re-aim.org. Accessed Janaury 19, 2018.

[26] R.E. Lee, E.G. Soltero, T.A. Ledoux, et al., Sustainability via active garden education (SAGE): Translating policy to practice to meet physical activity and nutrition guidelines in early care and education, J School Health. (2019) (In press).

[27] US Census Bureau. QuickFacts: Phoenix City, Arizona; UNITED STATES. https:// www.census.gov/quickfacts/fact/table/phoenixcityarizona,US/PST045216. Accessed May 29, 2018.

[28] Bureau of Child Care Licensing, http://www.azdhs.gov/als/childcare.

[29] T.A. Ledoux, K. Watson, A. Barnett, N.T. Nguyen, J.C. Baranowski, T. Baranowski, Components of the diet associated with child adiposity: a cross-sectional study, J. Am. Coll. Nutr. 30 (6) (2011) 536-546.

[30] R.E. Lee, C. Cubbin, Neighborhood context and youth cardiovascular health behaviors, Am. J. Public Health 92 (3) (2002) 428-436.

[31] A.L. Roy, D. Hughes, H. Yoshikawa, Intersections between nativity, ethnic density, and neighborhood SES: using an ethnic enclave framework to explore variation in Puerto Ricans' physical health, Am. J. Community Psychol. 51 (3-4) (2013) 468-479.

[32] F.E. Vaca, S. Trevino, A. Riera, E. Meyer, C.L. Anderson, Contextualizing exposures and experiences of behaviors that influence the risk of crash injury in Latino adolescent males, Ann Adv Automat Med. 56 (2012) 79-86.

[33] US Census Bureau. American FactFinder. 2010; https://factfinder.census.gov/ faces/nav/jsf/pages/index.xhtml. (Accessed May 29, 2018).

[34] US Office of Personnel Management. Child Care Resources Handbook. https:// www.opm.gov/policy-data-oversight/worklife/reference-materials/child-careresources-handbook/. Accessed May 31, 2018.

[35] The National Association for the Education of Young Children, http://www.naeyc org/, (2014).

[36] Physical Activity Guidelines for Americans, http://www.health.gov/paguidelines/ guidelines/default.aspx, (2008).

[37] Choose MyPlate: Why Is Physical Activity Important? http://www.choosemyplate gov/printpages/PhysicalActivity/physical-activity.why.pdf, (2008).

[38] Growing up Wild: Exploring Nature with Young Children, http://projectwild.org/ GrowingUpWILD/sendmail/order.htm.

[39] Grow it, Try it, like it! Preschool Fun with Fruits and Vegetables, http://www.fns 
usda.gov/tn/grow-it-try-it-it, (2013)

[40] Eat Well Play Hard Program: Nutrition Workshops for Children, Parents and Staff at Child Care Centers, http://www.nyc.gov/html/doh/html/living/schoolnutrition.shtml, (2013).

[41] Teaching Children to Listen to their Bodies, http://www.extension.org/pages/ 65014/teaching-children-to-listen-to-their-bodies\#.U4UrZXJdV8F, (2013).

[42] L.L. Birch, J.O. Fisher, K.K. Davison, Learning to overeat: maternal use of restrictive feeding practices promotes girls' eating in the absence of hunger, Am. J. Clin. Nutr. 78 (2) (2003) 215-220.

[43] T.M. Cutting, J.O. Fisher, K. Grimm-Thomas, L.L. Birch, Like mother, like daughter: familial patterns of overweight are mediated by mothers' dietary disinhibition, Am. J. Clin. Nutr. 69 (4) (1999) 608-613.

[44] C. Hill, C.H. Llewellyn, J. Saxton, et al., Adiposity and 'eating in the absence of hunger' in children, Int. J. Obes. 32 (10) (2008) 1499-1505.

[45] J.R. Pieper, K.D. Laugero, Preschool children with lower executive function may be more vulnerable to emotional-based eating in the absence of hunger, Appetite 62 (2013) 103-109.

[46] A.T. Ahmed, C.E. Oshiro, S. Loharuka, R. Novotny, Perceptions of middle school educators in Hawai'i about school-based gardening and child health, Hawaii Med. J. 70 (7) (2011) 11-15 Suppl 1.

[47] Super Empowerment, www.dangerrangers.com, (2011) Accessed September 5, 2018.

[48] National Program for Playground Safety, Playground Safety, www. playgroundsafety.org, (2014) (Accessed September 5, 2018).

[49] Nemous Foundation, Kids Health for Kids, www.kidshealth.org, (2014) (Accessed September 5, 2018).

[50] A. Delbecq, A. Vad De Ven, D. Gustafson, Group Techniques for Program Planning: A Guide to Nominal Group and Delphi Processes, Scott Foresman, Glenview, IL, 1975.

[51] A. MacPhail, Nominal Group Technique: a useful method for working with young people, Br. Educ. Res. J. 27 (2) (2001) 161-170.

[52] T.M. O'Connor, E. Cerin, S.O. Hughes, et al., What Hispanic parents do to encourage and discourage 3-5 year old children to be active: a qualitative study using nominal group technique, Int. J. Behav. Nutr. Phys. Act. 10 (2013) 93.

[53] A. Van de Ven, A. Delbecq, The effectiveness of nominal, Delphi, and interactive group decision making process, Acad. Manag. J. 17 (4) (1974) 605-621.

[54] R.K. Golley, G.A. Hendrie, A. Slater, N. Corsini, Interventions that involve parents to improve children's weight-related nutrition intake and activity patterns - what nutrition and activity targets and behaviour change techniques are associated with intervention effectiveness? Obes. Rev. 12 (2) (2011) 114-130.

[55] M. Patton, Qualitative Evaluation and Research Study, 2, Sage Publicaitons, Newbury Park, CA, 1990.

[56] P.A. Estabrooks, R.E. Glasgow, Translating effective clinic-based physical activity interventions into practice, Am. J. Prev. Med. 31 (4 Suppl) (2006) S45-S56.

[57] ActiGraph. ActiGraph Activity Monitor: wGT3X-BT. https://actigraphcorp.com/ actigraph-wgt3x-bt/. Accessed May 29, 2018.

[58] N.C. Crespo, K. Corder, S. Marshall, et al., An examination of multilevel factors that may explain gender differences in children's physical activity, J. Phys. Act. Health 10 (7) (2013) 982-992.

[59] A.H. Chen, J.F. Sallis, C.M. Castro, et al., A home-based behavioral intervention to promote walking in sedentary ethnic minority women: project WALK, Womens Health. 4 (1) (1998) 19-39.

[60] T.M. O'Connor, E. Cerin, S.O. Hughes, et al., Psychometrics of the preschooler physical activity parenting practices instrument among a Latino sample, Int. J. Behav. Nutr. Phys. Act. 11 (2014) 3.

[61] R.E. Lee, S.K. Mama, A.V. Medina, et al., Multiple measures of physical activity, dietary habits and weight status in African American and Hispanic or Latina women, J. Community Health 36 (6) (2011) 1011-1023.

[62] L. Choi, Z. Liu, C.E. Matthews, M.S. Buchowski, Validation of accelerometer wear and nonwear time classification algorithm, Med. Sci. Sports Exerc. 43 (2) (2011) $357-364$.

[63] N.F. Butte, W.W. Wong, J.S. Lee, A.L. Adolph, M.R. Puyau, I.F. Zakeri, Prediction of energy expenditure and physical activity in preschoolers, Med. Sci. Sports Exerc. 46 (6) (2014) 1216-1226.

[64] J.S. Gubbels, S.P. Kremers, A. Stafleu, P.C. Dagnelie, N.K. de Vries, C. Thijs, Childcare environment and dietary intake of 2- and 3-year-old children, J. Hum. Nutr. Diet. 23 (1) (2010) 97-101.

[65] A. Magarey, J. Watson, R.K. Golley, et al., Assessing dietary intake in children and adolescents: considerations and recommendations for obesity research, Int. J. Pediatr. Obes. 6 (1) (2011) 2-11.

[66] M.L. Baglio, S.D. Baxter, C.H. Guinn, W.O. Thompson, N.M. Shaffer, F.H. Frye, Assessment of interobserver reliability in nutrition studies that use direct observation of school meals, J. Am. Diet. Assoc. 104 (9) (2004) 1385-1392.

[67] S.L. Richter, L.M. Vandervet, L.A. Macaskill, M.I. Salvadori, J.A. Seabrook, P.D. Dworatzek, Accuracy and reliability of direct observations of home-packed lunches in elementary schools by trained nutrition students, J. Acad. Nutr. Diet. 112 (10) (2012) 1603-1607.

[68] D. Feskanich, B.H. Sielaff, K. Chong, I.M. Buzzard, Computerized collection and analysis of dietary intake information, Comput. Methods Prog. Biomed. 30 (1) (1989) 47-57.

[69] P. Ziegler, C. Hanson, M. Ponza, T. Novak, K. Hendricks, Feeding infants and toddlers study: meal and snack intakes of Hispanic and non-Hispanic infants and toddlers, J. Am. Diet. Assoc. 106 (1) (2006) S107-S123 Suppl 1.

[70] M.S. Faith, R.I. Berkowitz, V.A. Stallings, J. Kerns, M. Storey, A.J. Stunkard, Eating in the absence of hunger: a genetic marker for childhood obesity in prepubertal boys? Obesity (Silver Spring) 14 (1) (2006) 131-138.
[71] J.O. Fisher, L.L. Birch, Restricting access to foods and children's eating, Appetite 32 (3) (1999) 405-419.

[72] E.G. Soltero, T. Ledoux, R.E. Lee, Feasibility and acceptability of adapting the eating in the absence of hunger assessment for preschoolers in the classroom setting, Eat. Behav. 19 (2015) 68-71.

[73] T.M. O'Connor, S.O. Hughes, K.B. Watson, et al., Parenting practices are associated with fruit and vegetable consumption in pre-school children, Public Health Nutr. 13 (1) (2010) 91-101.

[74] B.F. Arnold, D.R. Hogan, J.M. Colford Jr., A.E. Hubbard, Simulation methods to estimate design power: an overview for applied research, BMC Med. Res. Methodol. 11 (2011) 94.

[75] T. Marsh, K.W. Cullen, T. Baranowski, Validation of a fruit, juice, and vegetable availability questionnaire, J. Nutr. Educ. Behav. 35 (2) (2003) 93-97.

[76] P.A. Estabrooks, N.C. Gyurcsik, Evaluating the impact of behavioral interventions that target physical activity: issues of generalizability and public health, Psychol. Sport Exerc. 4 (1) (2009) 41-55.

[77] Program Evaluation Tip Sheet: Reach and Impact, http://www.cdc.gov/DHDSP/ programs/nhdsp_program/docs/Reach_Impact_Tip_Sheet.pdf, (2011).

[78] R.E. Glasgow, L.M. Klesges, D.A. Dzewaltowski, P.A. Estabrooks, T.M. Vogt, Evaluating the impact of health promotion programs: using the RE-AIM framework to form summary measures for decision making involving complex issues, Health Educ. Res. 21 (5) (2006) 688-694.

[79] R.E. Lee, A.V. Medina, S.K. Mama, et al., Health is power: an ecological, theorybased health intervention for women of color, Contemp Clin Trials. 32 (6) (2011) 916-923.

[80] J.J. Dziak, L.M. Collins, A.T. Wagner, FactorialPowerPlan Users' Guide (Version 1.0), University Park: The Methodology Center, Penn State (2013).

[81] National Association for Sport and Physical Education, Active Start: A Statement of Physical Activity Guidelines for Children Birth to Five Years, NASPE Publications, Reston, VA, 2009.

[82] S.Y. Kimm, N.W. Glynn, A.M. Kriska, et al., Decline in physical activity in black girls and white girls during adolescence, N. Engl. J. Med. 347 (10) (2002) 709-715.

[83] R.R. Pate, K. McIver, M. Dowda, W.H. Brown, C. Addy, Directly observed physical activity levels in preschool children, J Sch Health. 78 (8) (2008) 438-444.

[84] R.R. Pate, K.A. Pfeiffer, S.G. Trost, P. Ziegler, M. Dowda, Physical activity among children attending preschools, Pediatrics 114 (5) (2004) 1258-1263.

[85] J.J. Reilly, J. Coyle, L. Kelly, G. Burke, S. Grant, J.Y. Paton, An objective method for measurement of sedentary behavior in 3- to 4-year olds, Obes. Res. 11 (10) (2003) 1155-1158.

[86] L. Wolfenden, J. Jones, C.M. Williams, et al., Strategies to improve the implementation of healthy eating, physical activity and obesity prevention policies, practices or programmes within childcare services, Cochrane Database Syst. Rev. 10 (2016) CD011779.

[87] J.N. Larson, T.A. Brusseau, B. Chase, A. Heinemann, J.C. Hannon, Youth physical activity and enjoyment during semi-structured versus unstructured school recess, Open J Prev Med. 4 (8) (2014) 631.

[88] P.W. Scruggs, S.K. Beveridge, D.L. Watson, Increasing children's school time physical activity using structured fitness breaks, Pediatr. Exerc. Sci. 15 (2) (2003) $156-169$.

[89] R.E. Lee, K.M. McAlexander, J.A. Banda, Reversing the Obesogenic Environment, Human Kinetics, Champaign, IL, 2011.

[90] The CONSORT Statement, http://www.consort-statement.org/, (2014).

[91] P. Estabrooks, D.A. Dzewaltowski, R.E. Glasgow, L.M. Klesges, Reporting of validity from school health promotion studies published in 12 leading journals, 1996-2000, J Sch Health. 73 (1) (2003) 21-28.

[92] A. Ammerman, G. Corbie-Smith, D.M. St George, C. Washington, B. Weathers, B. Jackson-Christian, Research expectations among African American church leaders in the PRAISE! Project: a randomized trial guided by community-based participatory research, Am. J. Public Health 93 (10) (2003) 1720-1727.

[93] B.B. Boyer, G.V. Mohatt, R.L. Pasker, E.M. Drew, K.K. McGlone, Sharing results from complex disease genetics studies: a community based participatory research approach, Int J Circumpolar Health. 66 (1) (2007) 19-30.

[94] N.P. Correa, N.G. Murray, C.A. Mei, et al., CAN DO Houston: a community-based approach to preventing childhood obesity, Prev. Chronic Dis. 7 (4) (2010) A88.

[95] N.H. Farag, W.E. Moore, D.M. Thompson, C.E. Kobza, K. Abbott, J.E. Eichner, Evaluation of a community-based participatory physical activity promotion project: effect on cardiovascular disease risk profiles of school employees, BMC Public Health 10 (2010) 313.

[96] J.M. Jurkowski, M. Mosquera, B. Ramos, Selected cultural factors associated with physical activity among Latino women, Women Health Iss. 20 (3) (2010) 219-226.

[97] G.V. Mohatt, R. Plaetke, J. Klejka, et al., The Center for Alaska Native Health Research Study: a community-based participatory research study of obesity and chronic disease-related protective and risk factors, Int J Circumpolar Health. 66 (1) (2007) 8-18.

[98] R. Pazoki, I. Nabipour, N. Seyednezami, S.R. Imami, Effects of a community-based healthy heart program on increasing healthy women's physical activity: a randomized controlled trial guided by Community-based Participatory Research (CBPR), BMC Public Health 7 (2007) 216.

[99] B.M. Reininger, C.S. Barroso, L. Mitchell-Bennett, et al., Process evaluation and participatory methods in an obesity-prevention media campaign for Mexican Americans, Health Promot. Pract. 11 (3) (2010) 347-357.

[100] S. Wilcox, D. Parra-Medina, G.M. Felton, M.B. Poston, A. McClain, Adoption and implementation of physical activity and dietary counseling by community health center providers and nurses, J. Phys. Act. Health 7 (5) (2010) 602-612.

[101] S.K. Mama, E.G. Soltero, T.A. Ledoux, M.R. Gallagher, R.E. Lee, Solving the obesity 
epidemic: voices from the community, Nurs. Inq. 21 (3) (2014) 192-201.

[102] J.A. Bushar, J.S. Kendrick, H. Ding, C.L. Black, S.M. Greby, Text4baby influenza messaging and influenza vaccination among pregnant women, Am. J. Prev. Med. 53 (6) (2017) 845-853.

[103] A.M. Muller, S. Alley, S. Schoeppe, C. Vandelanotte, The effectiveness of e-\& mHealth interventions to promote physical activity and healthy diets in developing countries: a systematic review, Int. J. Behav. Nutr. Phys. Act. 13 (1) (2016) 109.

[104] E. Poorman, J. Gazmararian, R.M. Parker, B. Yang, L. Elon, Use of text messaging for maternal and infant health: a systematic review of the literature, Matern. Child Health J. 19 (5) (2015) 969-989. 